\title{
Program Pelatihan Gambar Teknik Menggunakan Aplikasi Autocad di SMK Muhammadiyah 3 Samarinda
}

\author{
Binyamin $^{1 *}$ Muhammad Noor Asnan ${ }^{2}$, Bagas Bayu Prasetyo ${ }^{3}$ dan Daniel Flawijaya \\ Ledau $^{4}$ \\ 1,3,4S1 Teknik Mesin, Universitas Muhammadiyah Kalimantan Timur \\ 2 S1 Teknik Sipil, Universitas Muhammadiyah Kalimantan Timur \\ e-mail: *1bin279@umkt.ac.id
}

\begin{abstract}
Vocational students need some skills that will be used when students finish their studies at school. One of the expected skills is the ability to draw using the AutoCAD program. Where the final ability is expected of the students will be able to create engineering drawings in the form of 2-D models. The purpose of the training program is to develop and improve the technical drawing skills of the XII class students in using the AutoCAD program. Therefore, the students of class XII SMK have the ability to draw machine components and other engineering drawings in 2-D format. The method used in this training program through pre-test instrument, AutoCAD module, discussion, display through slide how to make machine image in 2-D formats and practice how to make the engineering drawing then evaluated with post-test. The result of this program is the improvement of the ability of grade XII students in drawing machine components and other engineering drawings in 2-D format.
\end{abstract}

Keywords: AutoCAD, SMK, Engineering Drawing, 2-D

\begin{abstract}
Abstrak. Siswa-siswa SMK membutuhkan beberapa keahlian yang nantinya akan digunakan ketika siswa menyelesaikan studinya di sekolah. Salah keahlian yang diharapkan adalah kemampuan menggambar menggunakan program AutoCAD. Dimana kemampuan akhir yang diharapkan dari siswa nantinya adalah mampu membuat gambar dalam bentuk model 2-D. Tujuan dari program pelatihan adalah untuk mengembangkan dan meningkatkan kemampuan gambar teknik dari siswa kelas XII dalam menggunakan program AutoCAD. Dengan program pelatihan ini diharapkan siswa mampu membuat gambar komponen-komponen mesin dalam bentuk format gambar teknik 2-D. Sehingga siswa kelas XII SMK memiliki kemampuan menggambar komponen-komponen mesin dan gambar-gambar lainnya dalam format 2-D. Program pelatihan ini menggunakan metode melaui instrumen pre-test, modul AutoCAD, diskusi, menayangkan melalui slide cara pembuatan gambar mesin dalam format 2-D serta mempraktekkan cara membuat gambargambar teknik tersebut kemudian dievaluasi dengan pemberian post-test. Hasil dari program ini terjadi peningkatan kemampuan siswa kelas XII dalam menggambar komponen-komponen mesin dan gambar-gambar teknik lainnya dalam format 2-D.
\end{abstract}

Kata kunci: AutoCAD, SMK, Engineering Drawing, 2-D 


\section{Pendahuluan}

Kualitas kesehatan suatu bangsa ditentukan oleh kualitas kesehatan masyarakatnya hal ini tergambarkan pada indikator Indeks Pembangunan Manusia (IPM) yang terdapat tiga indikator kemajuan suatu negara, yakni indikator ekonomi, pendidikan (angka melek huruf) dan kesehatan. Sadar atas pentingnya akan kesehatan, maka pemerintah mengeluarkan Undang-undang No 36 tentang Kesehatan (Diana dkk, 2014). Peningkatan kualitas kesehatan masyarakat hendaknya di lakukan sejak dini. Hal ini dapat dilakukan pada tingkat sekolah, karena pada dasarnya sekolah merupakan wadah pendidikan siswa yang didalamnya diajarkan banyak hal termasuk dunia kesehatan (Arikunto, 2010). Pentingnya kesehatan dalam sekolah tertuang dalam Undang-undang Kesehatan tersebut pasal 79 terkait kesehatan sekolah. Pelaksanaan kesehatan di sekolah diatur pula dalam Peraturan Menteri Kesehatan (PERMENKES) No. 2269/Menkes/Per/X/2011 tentang penyelenggaraan Perilaku Hidup Bersih dan Sehat diberbagai tatanan termasuk Institusi Pendidikan (Daramusseng dan Julianti,2019).

Perilaku hidup bersih dan sehat pada tatanan sekolah dilakukan untuk menjamin kesehatan para siswa agar terhindar dari risiko penyakit akibat lingkungan sekolah. Salah satu yang masih teringat dibenak masyarakat Samarinda adalah ditemukannya permen yang mengandung narkoba di beberapa lingkungan sekolah di Samarinda. Jajanan ini berbentuk permen lolipop yang dijual berkisar Rp, 1000 hingga Rp. 3000 (Fivi dkk, 2014). Hal ini sangat merugikan bagi siswa karena akan menganggu kesehatannya kelak. Risiko lingkunagn lainnya adalah persebaran penyakit demam berdarah, dimana nyamuk Aedes Aegypti memiliki kebiasaan aktif pada pukul 06.00 pagi hingga 17.00 sore. Hal ini mengindikasikan bahwa terdapat peluang risiko terkena penyakit demam berdarah pada siswa sekolah pada aktivitasnya (Karaeng skk, 2016).

Melihat adanya potensi penyakit yang mengancam siswa dari berbagai penjuru, maka dirasa perlu adanya upaya preventif yang dilakukan secara aktif oleh siswa di sekolah (Gomo dkk, 2013). Adanya Usaha Kesehatan Sekolah di SMK Muhammadiyah 1 Samarinda dirasa masih belum maksimal karena fungsi UKS nya berupa tempat untuk mengobati dan tempat istirahat jika ada siswa yang sakit (Dinas Kesehatan Kota Samarinda, 2016). Padahal lebih dari itu, fungsi UKS bertujuan untuk memupuk kebiasaan hidup sehat dan mempertinggiderajat kesehatan peserta didik yang mencakup memiliki pengetahuan, sikap, dan keterampilan prinsip hidup sehat, sehat fisik, mental serta lingkungan. 
Kompetensi mencakup keterampilan, tugas, sikap dan apresiasi yang harus dimiliki oleh siswa agar dapat melaksanakan tugas-tugas yang dipelajarinya di sekolah sesuai dengan kemampuan yang diperlukan oleh dunia kerja.

CAD (Computer Aided Design) adalah program komputer yang memungkinkan seorang perancang (designer) untuk mendisain gambar rekayasa dengan mentransformasikan gambar geometris secara cepat. Sukarno, dkk. (2010) melakukan pengabdian di SMK Tarumajaya Kabupaten Bekasi melalui metode teori, praktek dan diskusi serta pemberian tugas langsung kepada peserta dan adanya peningkatan kompetensi mendesain menggunakan software CAD. Lapisa, dkk. (2017) melakukan pengabdian kepada siswa-siswa SMK Muhammadiyah Batusangkar Padang bertujuan untuk meningkatkan kompetensi siswa melalui pelatihan AutoCAD 2-D dan 3-D dengan menggunakan metode pemberian modul, diskusi, dan praktek langsung membuat gambar teknik 2-D dan 3-D. Patkur dan Wibowo (2013) mengembangkan sebuah modul pembelajaran pembelajaran AutoCAD di kelas X TPM SMKN 1 Sidoarjo. Mereka mengembangkan model 4D (Four D Model) melalui tahap pendefinisian, perancangan, pengembangan dan penyebaran. Hasil prosentase pembelajaran dari penggunaan modul sebesar $88,307 \%$ serta peningkatan aktifitas belajar siswa.

Kompetensi siswa SMK Muhammadiyah 3 Samarinda perlu ditingkatkan, terutama dalam penguasaan perangkat lunak AutoCAD. Diharapkan lulusan siswa SMK Muhammadiyah 3 Samarinda lebih siap bersaing dalam memasuki dunia kerja. Minimal lulusan siswa SMK Muhammadiyah 3 Samarinda dapat memenuhi dan lolos syarat administrasi serta syarat wajib mampu mengoperasikan Ms. Office dan AutoCAD. Melalui pengabdian masyarakat ini, diharapkan siswa SMK mempunyai kemampuan dasar mengoperasikan AutoCAD dan merancang gambar teknik 2-D. Melalui pelatihan ini, diharapkan siswa SMK nantinya bisa langsung bekerja di dunia usaha dan dunia industri serta mampu mengembangkan kemampuannya tidak hanya perancangan di bidang teknik, namun juga dalam bidang kehidupan lainnya 
Kegiatan pengabdian masyarakat ini bertujuan untuk mengembangkan dan mensukseskan pembangunan menuju tercapainya masyarakat yang maju, adil dan sejahtera. Termasuk juga usaha untuk meningkatkan kemampuan masyarakat dalam sasaran pemecahan masalah sendiri. Secara khusus tujuan pengabdian masyarakat dalam kegiatan ini adalah untuk memotivasi, melatih dan membimbing keterampilan siswa-siswa SMK Muhammadiyah 3 Samarinda untuk meningkatkan dan mengembangkan keterampilannya dalam bidang AutoCAD dan dalam perancangan objek gambar teknik 2-D.

Pengabdian ini diharapkan mampu memberikan peningkatan kompetensi dan keterampilan siswa-siswa SMK Muhammadiyah 3 Samarinda dalam bidang mengoperasikan perangkat lunak AutoCAD dan perancangan dan menggambar objek 2-D, sehingga siswa-siswa SMK Muhammadiyah 3 Samarinda percaya diri dalam menghadapi persaingan dunia kerja.

\section{Metode}

Kegiatan ini menggunakan metode Quasi Experiment dengan menggunakan pendekatan kuantitatif. Populasi sampel meliputi 20 orang siswa Jurusan Teknik Kendaraan Ringan (Otomotif) dan Alat Berat. Data kegiatan dikumpulkan dari hasil pre-test dan posttest pencapaian standar kompetensi siswa terhadap pelatihan yang diberikan. Teknik analisis data yang digunakan adalah teknik analisis data statistik deskriptif. Metode yang digunakan pada pelatihan ini meliputi:

\section{Metode ceramah dan tanya jawab}

Metode ini digunakan untuk menyajikan informasi umum tentang teori umum mengenai keunggulan AutoCad, perbedaan masing-masing command utility, commanddraw dan command editing. AutoCad memerlukan penyajian gambar langsung, sehingga pada saat penyajian materi melalui slide powerpoint diikuti dengan demontrasi langsung menggunakan bantuan software AutoCad.

\section{Metode demonstrasi dan praktek langsung}

Instruktur mendemontrasikan kepada peserta langkah-langkah perancangan dan pembuatan gambar 2-D dan 3-D melalui modul pelatihan yang diberikan kepada masingmasing peserta. Setelah instruktur pelatihan selesai menyajikan materi, peserta 
diberikan kesempatan untuk berlatih dan melakukan perancangan serta pembuatan gambar 2-D dan 3-D yang telah didemontrasikan oleh instruktur.

\section{Metode bimbingan}

Proses bimbingan dipandu langsung oleh panitia yang telah dibentuk oleh tim pengabdian masyarakat. Bimbingan dilakukan dan dipandu langsung dari kalangan dosen dan mahasiswa. Hal ni bertujuan untuk memberikan pelayanan kepada peserta pelatihan. Sehingga target capaian yang direncanakan oleh tim pengabdian masyarakat dapat tercapai.

Untuk keberhasilan suatu kegiatan maka perlu adanya pembuatan diagram alir dengan detail dapat dilihat pada gambar 1 


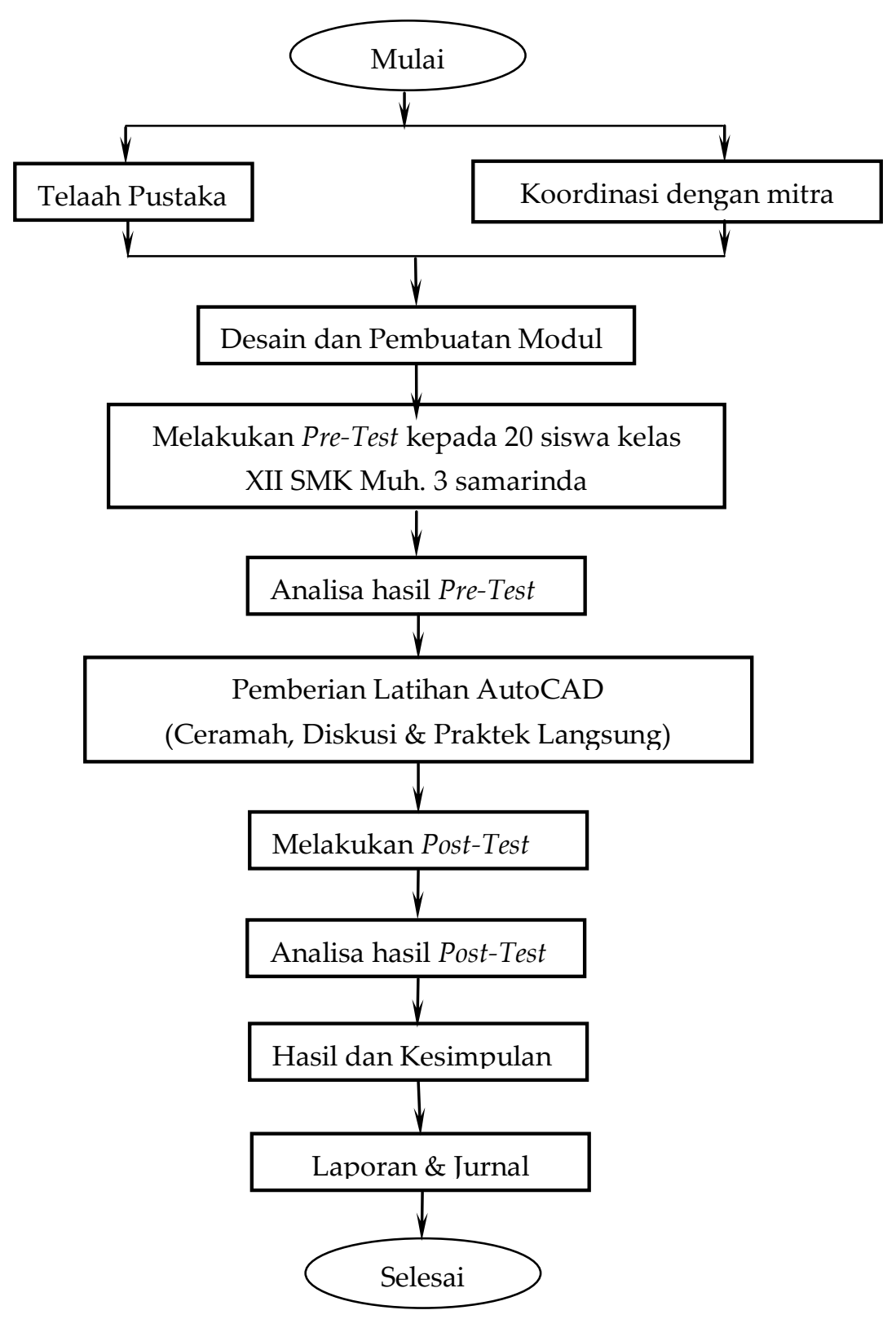

Gambar 1. Diagram Alir Kegiatan

\section{Rancangan Evaluasi}

Dilakukan dengan melihat hasil akhir tugas yang dihasilkan oleh peserta pelatihan. Hasil akhir pserta pelatihan dievaluasi bagaimana ukuran gambar, bentuk gambar dan ukuran gambar yang diminta lakukan oleh instruktur pelatihan. Untuk soal Pre-Test dapat dilihat pada gambar. 

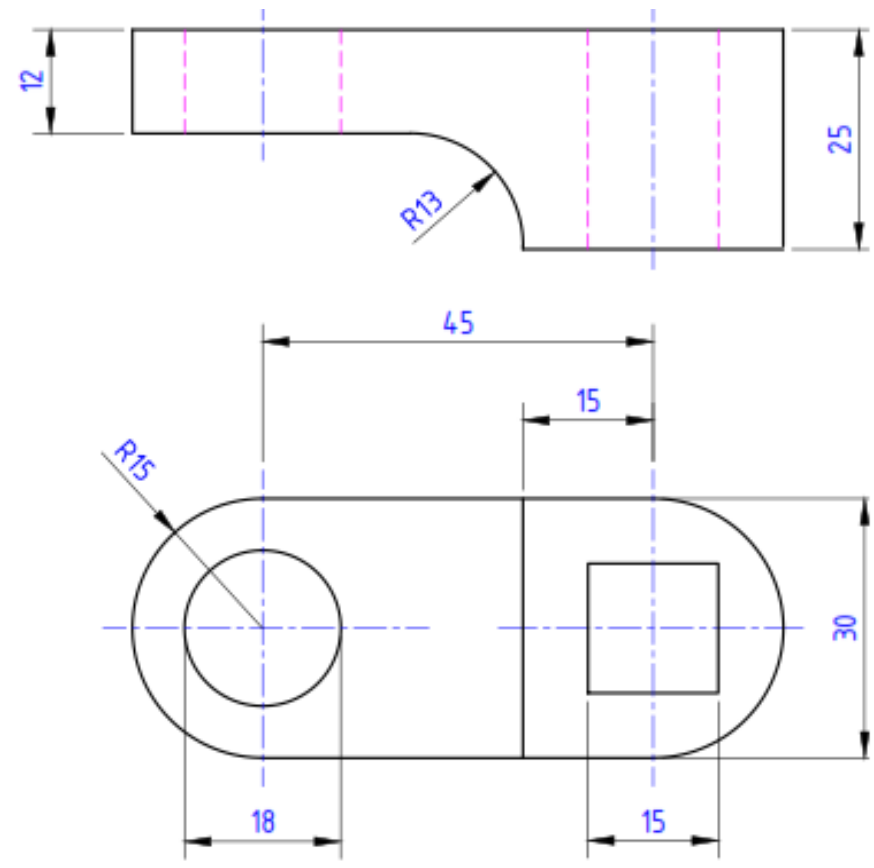

Gambar 2. Soal Pre-Test Author CAD 2-D

Berdasarkan hasil observasi awal (pre-test) dan hasil akhir (post-test) akan nampak perbedaan yang signifikan dari pemberian pelatihan yang diberikan. Untuk soal Post-Test dapat dilihat pada gambar 3 .
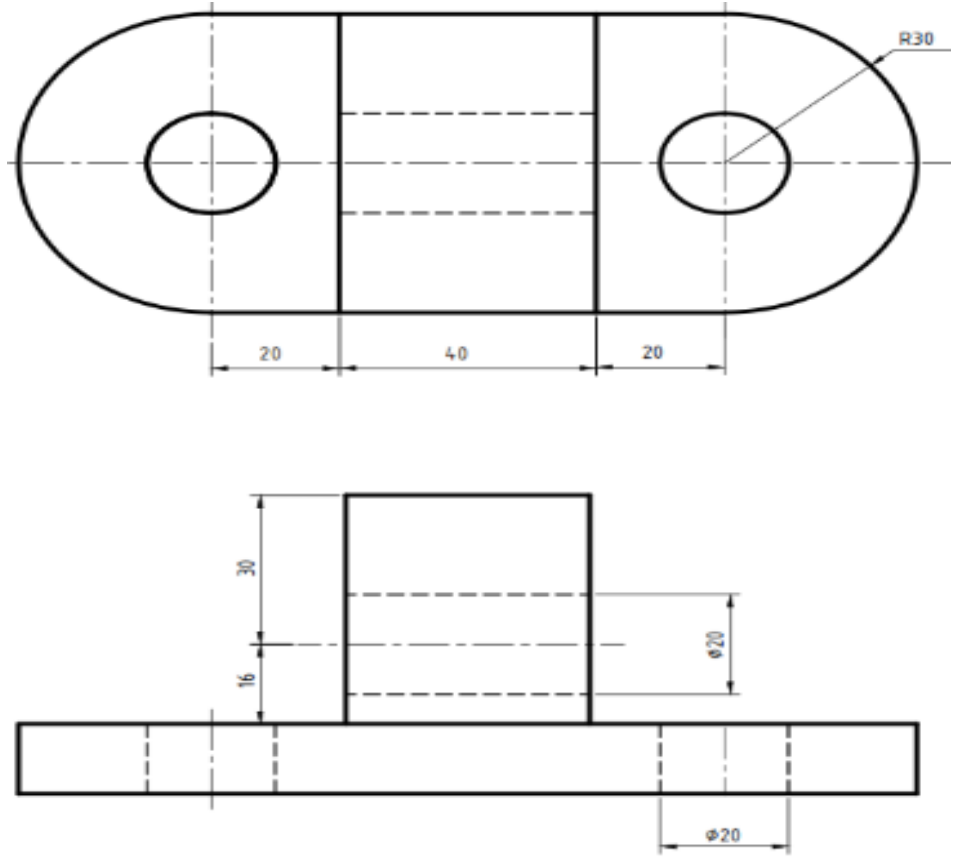

Gambar 3. Soal Post-Test AutoCAD 2-D 


\section{Hasil dan Pembahasan}

Salah satu bentuk kepedulian perguruan tinggi khususnya Universitas Muhammadiyah Kalimantan Timur kepada generasi penerus bangsa khususnya siswa SMK Muhammadiyah 3 Samarinda, dengan memberikan pelatihan yang berguna untuk meningkatkan dan mengembangkan bakat para siswa (gambar 4). Melalui kegiatan program pengabdian kepada masyarakat dengan tema "Program Pelatihan Gambar Teknik Menggunakan Aplikasi AutoCAD di SMK Muhammadiyah 3 Samarinda".

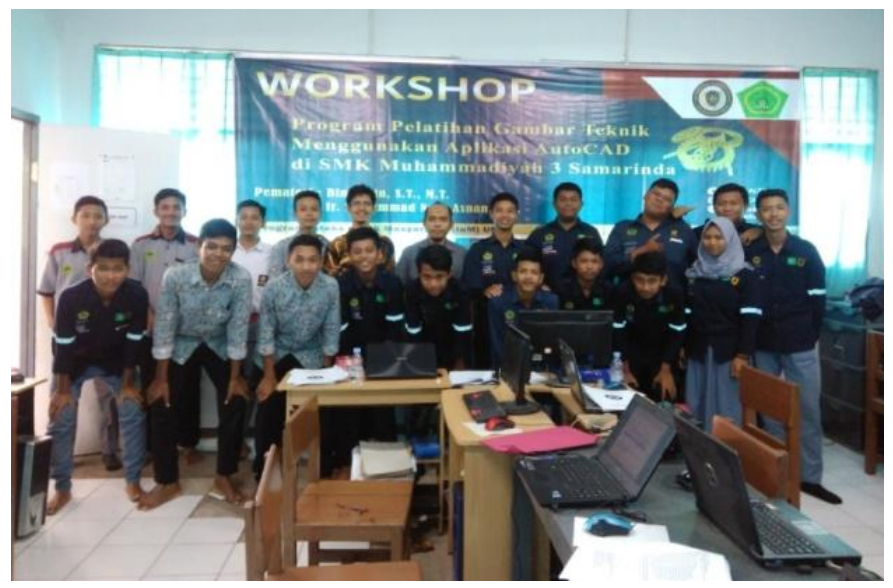

Gambar 4. Foto bersama pemateri dengan peserta pelatihan

Materi pelatihan dalam program pengabdian masyarakat ini difokuskan pada kemampuan akhir para siswa untuk dapat melakukan perancangan gambar 2-D disertai dengan pemberian ukuran gambar. Program pelatihan ini didukung oleh laboratorium komputer SMK Muhammadiyah 3 Samarinda. Sasaran dari pengabdian masyarakat ini adalah siswa kelas XII Jurusan Teknik Kendaraan Ringan (Otomotif) dan Alat Berat SMK Muhammadiyah 3 Samarinda karena akan sangat dibutuhkan ketika mereka bekerja di dunia industri.

Melalui kegiatan pengabdian kepada masyarakat yang diselenggarakan oleh Prodi Teknik Mesin UMKT, maka kami tertarik untuk memberikan pelatihan mengambar teknik menggunakan aplikasi AutoCAD di SMK Muhammadiyah 3 Samarinda (gambar 5). Kebutuhan penguasaan software AutoCAD sangat penting bagi siswa kelas XII ketika lulus dari SMK nantinya, kemampuan ini menjadi syarat wajib jika ingin bergabung dengan

perusahaan. Banyak perusahaan mencantumkan syarat untuk bergabung bagi lulusan SMK harus menguasai computer dalam hal Ms. Office dan AutoCAD. 


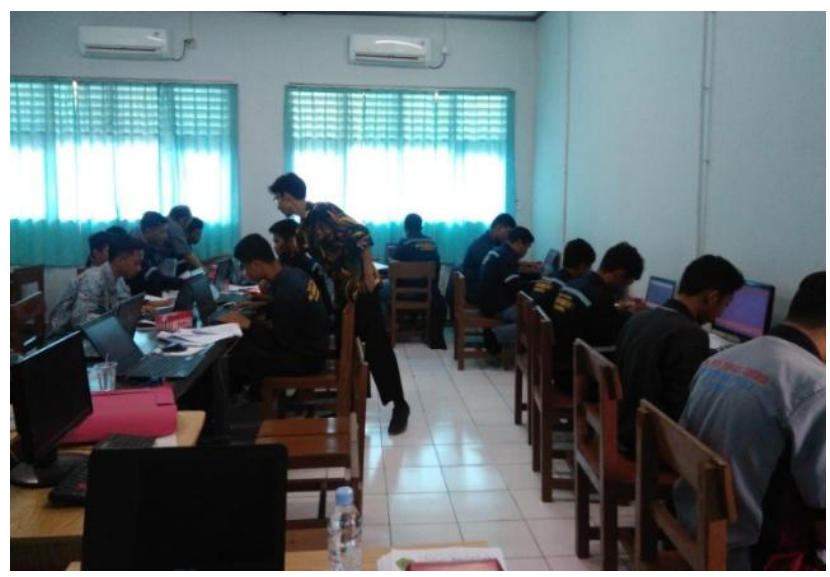

\section{Gambar 5. Bimbingan langsung kepada peserta pelatihan}

Target luaran pada kegiatan ini yang diharapkan adalah sebagai berikut:

1. Pembuatan modul pelatihan dasar gambar teknik menggunakan aplikasi AutoCAD

2. Pendampingan proses pembautan gambar teknik dengan harapan mampu mendapatkan pengetahuan dan ketrampilan dalam mendesain komponen mesin

3. Gambar-gambar teknik hasil pelatihan yang dilakukan siswa-siswa SMK Muhammadiyah 3 Samarinda

Kegiatan pengabdian masyarakat (IuM) dilaksanakan selama 3 (tiga) hari pada tanggal 16, 19 dan 20 April 2018 di laboratorium komputer SMK Muhammadiyah 3 Samarinda. Bentuk kegiatan ini berupa pemberian pre-test, workshop dan post-test. Kegiatan ini dalam bentuk pemberian pelatihan (workshop) gambar teknik menggunakan aplikasi AutoCAD kepada 20 orang siswa kelas XII SMK Muhammadiyah 3 Samarinda memberikan pengalaman baru, karena pada sekolah tersebut belum tersedia penggunaan aplikasi tersebut pada kurikulum pembelajaran.

Hasil evaluasi bentuk penilaian kegiatan ini didapatkan dari pemberian post-test kepada peserta pelatihan untuk mengetahui efektifitas dan keberhasilan kegiatan pelatihan yang dilaksanakan selama satu hari penuh (8 jam). Setelah dilakukannnya post-test lebih dari $80 \%$ peserta mampu mengerjakan persoalan gambar teknik menggunakan aplikasi AutoCAD dengan baik dan benar bisa dilihat pada gambar 6 . 


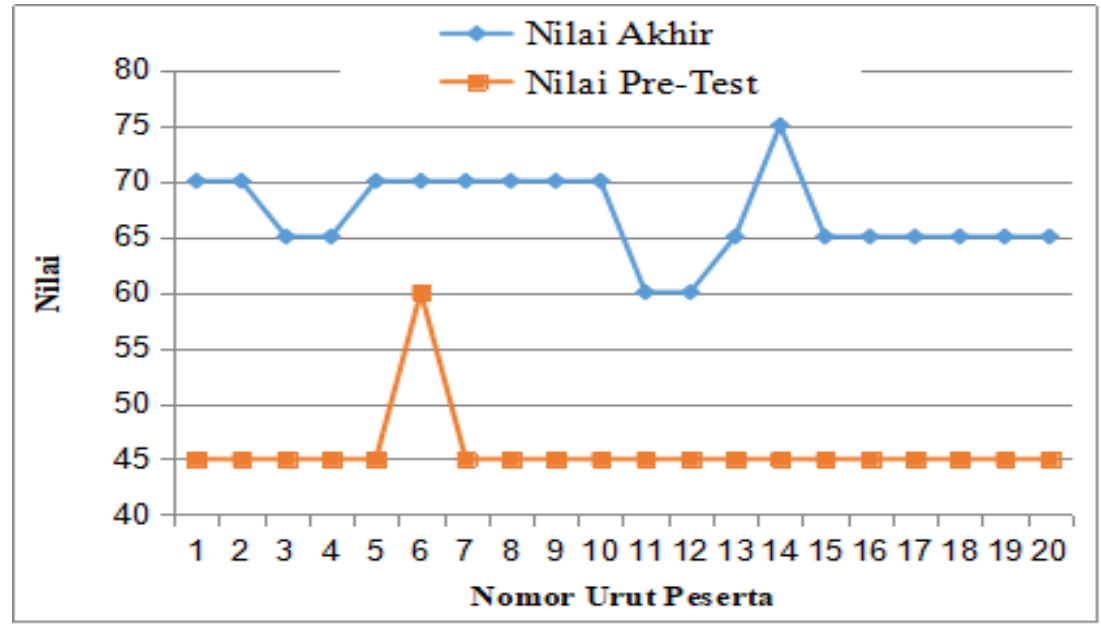

\section{Gambar 6. Nilai Peserta Pelatihan AutoCAD}

\section{Simpulan}

Dalam kegiatan program pelatihan gambar teknik menggunakan aplikasi AutocAD yang diberikan kepada siswa kelas XII SMK Muhammadiyah 3 Samarinda yang dilaksanakan pada tanggal 16 - 20 April 2018 dapat berjalan sesuai dengan rencana. Hasil yang dicapai peserta pelatihan sesuai dengan tujuan program yaitu meningkatnya pengetahuan dan keterampilan para siswa dalam perancangan gambar teknik 2-D menggunakan aplikasi AutoCAD.

\section{Daftar Pustaka}

Heri Zezen I, Sudarna, Supriadi, (2001), Risalah Praktikum Perancangan Sistem Kerja dan Ergonomi, Teknik Industri, Universitas Komputer Indonesia, Bandung.

Kurland K. S. (2012). AutoCAD 2013, 2D Tutorials. Autodesk Inc.

Lapisa R., Basri I.Y., Arif A. dan Saputra H. D. (2017). Peningkatan Kompetensi Siswa Melalui Pelatihan AutoCAD. Jurnal Inovasi, Vokasional dan Teknologi. Vol. 17 (2).

Patkur, M. dan Wibowo T. W. (2013). Pengembangan Modul Pembelajaran AutoCAD untuk Meningkatkan Efektivitas Pembelajaran Siswa Kelas X TPM di SMKN 1 Sidoarjo. JPTM. Vol. 01(03). 86-96. 